\title{
Changes in quality of life and functional capacity after lung transplantation: A single-center experience
}

\author{
Susanna Ricotti1, Valentina Martinelli2, Patrick Caspani1, Serena Monteleone1, \\ Elena Dalla Toffola1, Lucia Petrucci', Catherine Klersy³, the Collaborative Group \\ of Quality of Life in Heart and Lung Transplant ${ }^{4}$ \\ 1 Physical Medicine and Rehabilitation Unit, IRCCS Policlinico San Matteo Foundation, University of Pavia \\ 2 Psychological Medicine, IRCCS Policlinico San Matteo Foundation, Department of Brain and Behavioral \\ Sciences, University of Pavia \\ 3 Service of Biometry and Clinical Epidemiology, IRCCS Policlinico San Matteo Foundation \\ 4 IRCCS Policlinico San Matteo Foundation, Pavia, Italy
}

\begin{abstract}
Lung transplantation (LT) increases the life expectancy of patients affected by end stage pulmonary disease; specifically, its ultimate aims are to improve survival and health related quality of life (HRQoL). The aim of the present longitudinal study was to determine the HRQoL trajectory and changes in functional capacity from time of entry in the waiting list for LT to 2 year after LT. The study included sixty-nine outpatients enrolled in a single medical center when they entered the waiting list for LT and who subsequently received it. They were then followed up over 2 years after LT. HRQoL was assessed by the physical and mental component summary (PCS and MCS) scores of the 36-item
\end{abstract}

Corresponding author: Valentina Martinelli, Psychological Medicine, IRCCS San Matteo Foundation, P.le Golgi 19, 27100 Pavia, Italy.

Tel. +39.0382.502051 - Fax: +39.0382.502075.

E-mail: valentina.martinelli@unipv.it

Key words: Functional capacity; quality of life; lung transplantation; survival; Saint George's Respiratory Questionnaire; psychological distress.

The Collaborative Group of Quality of Life in Heart and Lung Transplant, IRCCS Policlinico San Matteo Foundation, Pavia, includes:

Physical Medicine and Rehabilitation Unit: E. Dalla Toffola, S. Ricotti, L. Petrucci

Division of Cardiac Surgery: AM. D'Armini, C. Pellegrini

Division of Pneumology: A. Cascina, F. Meloni, T. Oggionni

Psychological Medicine: C. Catania, G. Meroni, D. Rizzelli, P. Politi

Conflict of interest: The authors have no conflict of interest to disclose.

Received for publication: 8 June 2017

Accepted for publication: 5 November 2017

(C) Copyright S. Ricotti et al., 2017

Tipografia PI-ME Editrice, Italy

Monaldi Archives for Chest Disease 2017; 87:831

doi: 10.4081/monaldi.2017.831

This article is distributed under the terms of the Creative Commons Attribution Noncommercial License (by-nc 4.0) which permits any noncommercial use, distribution, and reproduction in any medium, provided the original author(s) and source are credited.
Short Form Health Survey (SF-36) and Saint George's Respiratory Questionnaire (SGRQ). Psychological distress was evaluated with the General Health Questionnaire (GHQ), and functional capacity was investigated using the six-minute walk test (6MWT) and forced expiratory volume (FEV1). Patients showed low SF-36 PCS (30.5 \pm 7.8$)$ and SGRQ total $(61.8 \pm 17.5)$ scores at entry in the waiting list, but exhibited significant changes over time after LT $(\mathrm{p}<0.001)$. Furthermore, patients who showed an increase of at least 50\% in SF36 PCS and SGRQ scores at 6 months survived longer. Both FEV1 and 6MWT distance as well as GHQ scores significantly changed over time, with improvements occurring in the first 6 months after LT but no major changes thereafter. Out of the 69 patients enrolled, 32 died over a median follow-up of 51 months. Although mortality tended to be slightly higher for patients with lower HRQOL at the baseline assessment, this difference was not statistically significant. HRQoL evaluations appear critical in the follow-up of LT candidates, in particularly SGRQ, because of its specificity in targeting respiratory symptoms and functional wellbeing.

\section{Introduction}

Lung transplantation (LT) increases life expectancy in selected patients with end stage and otherwise incurable pulmonary disease, regardless of their native diagnosis [1]. Nonetheless, survival after lung transplant gradually decreases over time, from $79 \%$ to $60 \%$ at 1 and 3 years, respectively, to $45 \%$ at 5 years [2,3]. Data from Italian transplant registries have indicated a growth in the annual number of LTs performed in Italy, with 141 LTs being performed in 2013; among these patients, the survival rate after transplantation was $45.6 \%$ at 5 years, which is in line with international data. However, the mean time on the waiting list was still 1.3 years, with a mortality rate of $10.9 \%$ during the waiting period [4].

Along with survival, researchers' interest has increasingly focused on health-related quality of life (HRQoL) in evaluating how successful the outcome of LT is. In fact, the ultimate aim of the surgical procedure is not only to increase survival but also to improve quality of life $[5,6]$.

Previous studies have shown that LT results in significant improvements in HRQoL within the first 6 months after the procedure, which persists throughout the first year [7-9]. Thereafter, the trajectory of HRQoL is less clear, with patients' wellbeing being hampered by the complications and side effects of immunosuppressive therapy [10]. In fact, few studies have investigated HRQoL longitudinally within the same patients over the long term, and those that exist show substantial heterogeneity in methodology and approach [7]. 
The purpose of this exploratory investigation was to describe the HRQoL trajectory from the time of entry in the waiting list and throughout the first two years after LT in a single center longitudinal cohort and to assess functional capacity and survival after LT among patients of the same sample.

\section{Patients and Methods}

This was a longitudinal study involving patients who had enrolled in our center at their entry into the waiting list for LT, and had subsequently undergone the procedure. They were then followed up over 2 years. After our protocol was approved by our local ethical review board, we obtained all participants' informed consent. Data were collected via questionnaires administered in individual interviews and clinical assessments before LT and at 6, 12, and 24 months after. We did not mail any of the questionnaires. The inclusion criteria were survival at 6 months after LT, age over 18 years, and being able to read and write in Italian. Re-transplant recipients and heart and lung transplant recipients were excluded from the study.

Our initial sample comprised 69 patients enrolled between February 2001 and June 2013. Twelve patients died before the 6 months followup after LT, leaving 57 patients for the longitudinal assessment. No patients were excluded because of a lack of consent and for inability to read and write in Italian. However, initially, 2 patients were excluded because they were receiving a re-transplant and 3 because they were receiving a heart and lung transplant. Demographic, clinical, and functional characteristics and the HRQoL scores of patients included and excluded from the longitudinal assessment are summarized in Tables 1 and 2. Each patient underwent a clinical assessment and an interview, wherein information on their level of education, type of employment before and after LT, level of autonomy inside and outside home, and symptoms were collected. Functional capacity was evaluated by using percentage of predicted forced expiratory volume in the 1 st second (FEV1\% predicted) and the meters walked in a 6-minute walking test (6MWT). Psychological distress was investigated by administering the 30-item Italian Version of the General Health Questionnaire (GHQ) [11-13]. This questionnaire is used for detecting current non-psychotic disorders; scores range from 0 to 30 , with lower scores corresponding to better health. A threshold between 4 and 5 was used in the present study to identify patients with psychological distress.

\section{Health-related quality of life instruments}

Two different instruments were used to investigate generic (36-item Short Form Health Survey, SF-36) and disease-specific (Saint George's Respiratory Questionnaire, SGRQ) HRQoL [1,14,15]. Items not answered were treated as for questionnaire scoring instructions.

General HRQoL was measured using the internationally validated SF-36 [16-20]. In particular, we used the Italian version of the SF-36 (version 1.6), created by the International Quality of Life Assessment Project. This measure comprises eight domains: physical functioning, role limitations due to physical problems, bodily pain, general health, vitality, social functioning, role limitations due to emotional problems, and mental health. These domains are in turn aggregated into 2 norm-based summary scores: physical and mental component summary scores (PCS and MCS, respectively). These norm-based scores range from 0 to 100 , with higher scores indicating better HRQoL; 50 is the average for the healthy Italian reference population. The questionnaires were scored according to the SF-36 Manual. We used only the PCS and MCS scores in this present study to summarize generic HRQoL.
To investigate disease-specific HRQoL, we employed the SGRQ [2123], a standardized self-administered airway-disease-specific questionnaire containing 3 subscales: symptoms ( 8 items), activity (16 items), and impact (26 items). The questionnaires were scored according to the manual for the Italian version. Total scores range from 0 to 100 , with lower scores indicating better HRQoL. Unfortunately, no healthy-group-based norms are available for the general Italian population. Both the SF-36 and SGRQ showed reasonable internal consistency, as rated by a Cronbach's alpha. Specifically, the Cronbach's alphas for all items were 0.95 for SF-36 (excellent) and 0.8 for the SGRQ (good) [24].

\section{Statistical analysis}

Data were described using means and standard deviations (SD) or medians and $25-75^{\text {th }}$ percentiles if continuous and as numbers and percentages if categorical. Changes over time in HRQoL were assessed by using general linear models for repeated measures, with calculations of Huber-White robust standard errors to account for intra-patient correlations in longitudinal measures; $95 \%$ confidence intervals (95\% CIs) were computed for all estimates. The interactions of time with age, gender, and presence of bilateral LT were tested to determine any modifying effect on HRQoL profile over time by those with selected characteristics. We also fit the same models with FEV1\% predicted, 6MWT walking distance, and GHQ scores to assess the associations of HRQoL with patients' functional capacity over time. Survival after LT according to HRQoL was described using Kaplan Meier curves, and we computed mortality per 100 person-years (95\% CI). Comparisons of mortality were performed using the Cox model, and we report hazard ratios (HR) and 95\% CIs. For the purposes of analysis, HRQoL was dichotomized according to an a priori consensus between authors: HRQoL at entry in the waiting list was dichotomized in terms of its worst tertile, while during follow-up it was dichotomized according to changes in HRQoL of $\geq 50 \%$ at 6 months (as a $\geq 50 \%$ change was considered clinically relevant). To compare with Norman's [25] standard minimal clinical important difference (MCID) for changes in HRQoL, which corresponds to an effect size (mean change/SD) of 0.5 , we computed the effect sizes of the changes in HRQoL at 6 months in both the $<50 \%$ and $\geq 50 \%$ groups. Finally, the effect of HRQoL on midterm survival was assessed via a series of bivariate Cox models, while adjusting for age, gender, type of LT, FEV1\% predicted, 6MWT distance, and GHQ score. We could not perform a multivariate analysis given the insufficient number of events.

All statistical analyses were performed using Stata 13.1 (StataCorp, College Station, TX, USA). A 2-sided p-value of $<0.05$ was considered statistically significant. We did not perform corrections for multiple tests given the exploratory nature of the study.

\section{Results}

\section{Health related quality of life trajectory}

The 57 patients included in this longitudinal study (Table 3) showed clear impairments in PCS score (30.5, 95\% CI 28.3 to 32.7) in comparison to the population norm at entry in the waiting list, whereas their MCS score was rather similar (49.6, 95\% CI 46.7 to 52.5). SGRQ scores (total and subscales) showed marked impairment due to airway disease. However, significant changes over time $(\mathrm{p}<0.001)$ were observed for PCS and SGRQ (total and subscales) scores. In particular, HRQoL as measured by the PCS and SGRQ total increased significantly at 6 months $(\mathrm{p}<0.001)$, but exhibited no further changes thereafter. 
A $\geq 50 \%$ improvement in HRQoL was observed in $39 \%$ and $4 \%$ of study participants for the SF-36 PCS and MCS scores, respectively, and in 57\% of patients according to the SGRQ total. Furthermore, $\geq 50 \%$ improvement was found in $65 \%, 59 \%$, and $39 \%$ of participants according to the symptoms, impact, and activity subscales of the SGRQ, respectively. The increase in HRQoL in the $\geq 50 \%$ group was highly clinically relevant, being well above the 0.5 effect size of the MCID. Notably, the effect size was often above 0.5 in the $<50 \%$ group as well.

Changes in HRQoL were similar for males and females and for patients older and younger than $\mathbf{5 0}$ years. However, they tended to be worse for patients with unilateral as compared to bilateral LT, although statistical significance was observed only for the PCS ( $p=0.031)$. One patient died before 12 months, and 5 died between 12 and 24 months; these individuals were not considered further for the quality of life trajectory assessment. Diagnosis appeared to be associated with changes in PCS and SGRQ total scores ( $\mathrm{p}=0.005$ and $\mathrm{p}=0.0036$, respectively). Particularly, both PCS and SGRQ total scores improved at 6 months after LT for all diagnoses, but for cystic fibrosis, there was a constant but less remarkable amelioration at 12 months. All of the diagnoses remained stable at 24 months. Time on the waiting list was not associated with changes in HRQoL at any follow-up point.

Table 1. Clinical and socio-demographic characteristics of all patients at entry into the lung transplantation waiting list, according to their inclusion in the longitudinal study.

\begin{tabular}{|c|c|c|c|}
\hline & & $\begin{array}{c}\text { Included } \\
\text { (live at } 6 \text { months after LT) }\end{array}$ & $\begin{array}{c}\text { Excluded } \\
\text { (deceased within } 6 \text { months after LT) }\end{array}$ \\
\hline Total & & 57 & 12 \\
\hline Age, mean (SD) & & $49.87(11.80)$ & $56.27(4.88)$ \\
\hline Males, n (\%) & & $48(84.21)$ & $9(75)$ \\
\hline BMI, mean (SD) & & $25.19(4.19)$ & $26.45(5.03)$ \\
\hline Diagnosis, n (\%) & $\begin{array}{l}\text { Pulmonary fibrosis } \\
\text { Emphysema } \\
\text { Cystic fibrosis/Bronchiectasis } \\
\text { Pulmonary hypertension I } \\
\text { Pulmonary hypertension II } \\
\text { Other }\end{array}$ & $\begin{array}{l}31(54.4) \\
12(21.1) \\
9(15.8) \\
3(5.3) \\
1(1.8) \\
1(1.8)\end{array}$ & $\begin{array}{l}8(66.7) \\
2(16.7) \\
1(8.3) \\
0(0.0) \\
0(0.0) \\
1(8.3)\end{array}$ \\
\hline Transplant type, n (\%) & $\begin{array}{l}\text { Bilateral lung transplant } \\
\text { Right lung transplant } \\
\text { Left lung transplant }\end{array}$ & $\begin{array}{l}27(47.4) \\
19(33.3) \\
11(19.3) \\
\end{array}$ & $\begin{array}{l}4(33.3) \\
6(50.0) \\
2(16.7)\end{array}$ \\
\hline Comorbidities, n (\%) & $\begin{array}{l}\text { Diabetes } \\
\text { Cardiopathy } \\
\text { Peripheral neurologic dysfunction } \\
\text { Osteoporosis } \\
\quad \text { Iatrogenic } \\
\quad \text { Postmenopausal } \\
\quad \text { Senile } \\
\text { Secondary osteoporotic fractures }\end{array}$ & $\begin{array}{cc}8(14.0) & \\
8(14.0) & \\
2(3.5) & \\
15(26.3) & \\
& 13(86.7) \\
& 1(6.7) \\
& 1(6.7) \\
& \end{array}$ & $\begin{array}{ll}3(25.0) & \\
3(25.0) & \\
0(0.0) & \\
4(33.3) & \\
& 4(100.0) \\
& 0(0) \\
& 0(0) \\
2(16.7) & \end{array}$ \\
\hline Level of education, $n(\%)$ & $\begin{array}{l}<8 \text { years } \\
>8 \text { years }\end{array}$ & $\begin{array}{l}38(66.7) \\
19(33.3) \\
\end{array}$ & $\begin{array}{l}10(83.3) \\
2(16.7)\end{array}$ \\
\hline $\begin{array}{l}\text { Type of employment } \\
\text { pre-LT, } n(\%)\end{array}$ & $\begin{array}{l}\text { Freelancer/Self-employed worker } \\
\text { Officer or employee } \\
\text { Retired }\end{array}$ & $\begin{array}{c}15(26) \\
38(67) \\
4(7)\end{array}$ & $\begin{array}{l}5(41.7) \\
5(41.7) \\
2(16.6)\end{array}$ \\
\hline $\begin{array}{l}\text { Occupation suspended } \\
\text { pre-LT, n (\%) }\end{array}$ & $\begin{array}{l}\text { No } \\
\text { Yes (disease) } \\
\text { Yes (other) }\end{array}$ & $\begin{array}{c}7(13.2) \\
37(69.8) \\
9(17.0) \\
\end{array}$ & $\begin{array}{l}5(41.7) \\
5(41.7) \\
2(16.6)\end{array}$ \\
\hline $\begin{array}{l}\text { Level of autonomy } \\
\text { in and outdoors, } n(\%)\end{array}$ & $\begin{array}{l}\text { Living alone } \\
\text { Going out alone } \\
\text { Going out accompanied } \\
\text { Going upstairs } \\
\text { Always at home } \\
\text { Bedbound } \\
\text { Driving } \\
\text { Cycling } \\
\text { Motor-cycling }\end{array}$ & $\begin{array}{c}4(7.0) \\
34(62.9) \\
11(20.4) \\
36(63.2) \\
9(16.7) \\
2(5) \\
32(56.2) \\
4(7.0) \\
2(3.5)\end{array}$ & $\begin{array}{l}0(0.0) \\
7(58.3) \\
4(33.3) \\
8(66.7) \\
1(8.3) \\
0(0.0) \\
9(75.0) \\
1(8.3) \\
1(8.3)\end{array}$ \\
\hline Symptoms, n (\%) & $\begin{array}{l}\text { Dyspnea } \\
\text { Fatigue } \\
\text { Cough } \\
\text { Secretions } \\
\text { Osteomioarticular pain }\end{array}$ & $\begin{array}{l}53(98.2) \\
39(68.42) \\
32(56.1) \\
27(47.3) \\
24(42.0)\end{array}$ & $\begin{array}{l}11(91.7) \\
8(66.7) \\
7(58.3) \\
4(33.3) \\
6(50.0)\end{array}$ \\
\hline
\end{tabular}




\section{Functional capacity and psychological distress trajectories over time}

FEV1\% predicted, 6MWT distance, and GHQ significantly changed over time $(\mathrm{p}<0.001$, Table 3$)$. We particularly observed improvement in the first 6 months after LT and no major changes afterwards. These changes paralleled those observed for HRQoL and indeed a significant and consistent association between these two sets of variables was shown, with better HRQoL corresponding to better functioning and lower psychological distress.

\section{Survival}

Of the 69 patients initially enrolled in the study, 32 died over a median follow-up time of 51 months ( $25^{\text {th- }} 75^{\text {th }}$ percentile $\left.26-81\right)$. This corresponds to a mortality rate of 18 per 100 person-years (95\% CI 13-26). Twelve of them died between LT and the 6 months follow-up and could not be further considered in longitudinal assessments. Out of the 57 patients who survived to follow-up at 6 months, 20 died thereafter (16.3 per 100 person-years, $95 \% \mathrm{CI} 10.4-25.5)$. Although mortality tended to be slightly higher among patients with lower HRQoL at the pre-LT assessment, the difference was not statistically significant (Table 4). The same trend was observed after adjusting for age, sex, type of LT, FEV1\% predicted, 6MWT distance, and GHQ score. In our study sample, 11 patients (20\% of survivors) were employed at 1 -year follow up and 8 patients (16\%) at 2-year follow up, respectively.

Patients showing an increase of at least 50\% in the PCS and SGRQ scores at 6 months also tended to survive longer (Table 5). However, statistical significance was achieved only for SGRQ total score, with an approximately 3 -fold increase in survival among patients with greater improvements in HRQoL. These results were confirmed after adjusting for age, sex, type of LT, FEV1\% predicted, 6MWT distance, and GHQ score. When considering HRQoL as a continuous variable, significance relationships were observed between survival and SGRQ total and the activity and symptoms subscales (Table 5).

Table 2. Functional status, clinical characteristics, and HRQoL scores of all patients at entry in the waiting list, according to their inclusion in the longitudinal study

\begin{tabular}{lccc} 
& $\begin{array}{c}\text { Included } \\
\text { (alive at } \mathbf{6} \text { months after LT) }\end{array}$ & $\begin{array}{c}\text { Excluded } \\
\text { (deceased within } \mathbf{6} \text { months after LT) }\end{array}$ \\
\hline 6HQ $>$ 4 & 34 out of $50(68 \%)$ & 7 out of $8(87.5 \%)$ & $4(33.3 \%)$ \\
\hline 6MWT (meters) & $22(38.6 \%)$ & $121(206)$ & 0.42 \\
\hline Time on waiting list (months, median IQR) & $142(205)$ & $21.81(6.25-28.21)$ & 0.7 \\
\hline FEV1 (\% predicted) & $8.13(2.30-14.64)$ & $43.68 \pm 17.86$ & 0.035 \\
\hline SF-36 PCS & $43.19 \pm 20.78$ & $22.90 \pm 4.97$ & 0.75 \\
\hline SF-36 MCS & $30.49 \pm 7.79$ & $46.26 \pm 10.82$ & 0.005 \\
\hline SGRQ Overall & $49.59 \pm 10.37$ & $71.30 \pm 12.43$ & 0.22 \\
\hline SGRQ Symptoms & $61.75 \pm 17.48$ & $61.53 \pm 22.50$ & 0.06 \\
\hline SGRQ Activities & $56.45 \pm 22.66$ & $87.89 \pm 7.66$ & 0.56 \\
\hline SGRQ Impact & $75.21 \pm 18.66$ & $64.89 \pm 18.14$ & 0.04 \\
\hline
\end{tabular}

Table 3. Trajectory over time of HRQoL, GHQ, and functional status in 57 patients included in the longitudinal assessment.

\begin{tabular}{|c|c|c|c|c|c|c|}
\hline \multirow[t]{2}{*}{ HRQoL } & \multirow{2}{*}{$\begin{array}{l}\text { Pre-transplant } \\
\text { (mean, SD) }\end{array}$} & \multirow{2}{*}{$\begin{array}{c}\text { Model } \\
\text { p }\end{array}$} & \multirow[t]{2}{*}{$\mathbf{R} 2 \%$} & \multicolumn{3}{|c|}{$\begin{array}{r}\text { Post hoc comparisons } \\
\end{array}$} \\
\hline & & & & $\begin{array}{c}\Delta 6 \mathrm{~m}-\text { pre } \\
(\Delta \text { mean, } 95 \% \mathrm{CI})\end{array}$ & $\begin{array}{c}\Delta 12 \mathrm{~m}-6 \mathrm{~m} \\
(\Delta \mathrm{mean}, 95 \% \mathrm{CI})\end{array}$ & $\begin{array}{c}\Delta 24 \mathrm{~m}-12 \mathrm{~m} \\
(\Delta \text { mean, } 95 \% \mathrm{CI})\end{array}$ \\
\hline Patients evaluated & 57 & & & 45 & 41 & 44 \\
\hline \multicolumn{7}{|l|}{ SF36 } \\
\hline PCS & $30.5 \pm 7.8$ & $<0.001$ & $23.51 \%$ & $+12.5[9.5 \text { to } 15.6]^{*}$ & $-0.9[-4.8$ to 2.9$]$ & $+1.5[-2.3$ to 5.2$]$ \\
\hline MCS & $49.6 \pm 10.4$ & 0.15 & $2.22 \%$ & $+3.7[-0.1$ to 7.5$]$ & $-0.5[-4.3$ to 3.3$]$ & $-1.0[-4.2$ to 2.2$]$ \\
\hline \multicolumn{7}{|l|}{ SGRQ } \\
\hline Overall & $61.7 \pm 17.5$ & $<0.001$ & $28.10 \%$ & $-30.4[-36.8 \text { to } 23.9]^{*}$ & $+2.7[-3.6$ to 9.0$]$ & $-3.3[-10.4$ to 3.8$]$ \\
\hline Activity & $75.2 \pm 18.7$ & $<0.001$ & $22.95 \%$ & $-30.3[-38.4 \text { to } 22.3]^{*}$ & $+0.9[-7.2$ to 8.9$]$ & $-5.3[-14.8$ to 4.3$]$ \\
\hline Impact & $55.7 \pm 20.2$ & $<0.001$ & $25.90 \%$ & $-30.9[-37.6 \text { to } 24.1]^{*}$ & $+4.1[-2.8$ to 10.9$]$ & $-3.1[-10.1$ to 3.8$]$ \\
\hline Symptoms & $56.4 \pm 22.7$ & $<0.001$ & $26.75 \%$ & $-28.8[-37.0 \text { to } 20.7]^{*}$ & $+1.8[-4.6$ to 8.2$]$ & $-0.2[-7.9$ to 7.5$]$ \\
\hline GHQ score & $9.8 \pm 7.8$ & $<0.001$ & $6.50 \%$ & $-3.5[-6.4$ to -0.7$] *$ & $-1.0[-3.2$ to 1.3$]$ & $+0.1[-2.2$ to 2.4$]$ \\
\hline & n (\%) & & & OR (95\% CI) & OR $(95 \% \mathrm{CI})$ & OR (95\% CI) \\
\hline $\mathrm{GHQ} \geq 5$ & $34(68 \%)$ & $<0.001$ & $6.65 \%$ & $0.3(0.2 \text { to } 0.6)^{*}$ & $0.8(0.4$ to 1.5$)$ & $1.3(0.5$ to 3.3$)$ \\
\hline FEV1 (\% predicted) & $43.19 \pm 21$ & $<0.001$ & $26.68 \%$ & 28.76 [20.12 to 37.40$]$ & $0.49[-5.40$ to 4.43$]$ & $5.52[-0.08$ to 11.12$]$ \\
\hline 6MWT meters & $142 \pm 205$ & $<0.001$ & $27.03 \%$ & $272[187$ to 356$]$ & $-5[-74$ to 66$]$ & $2[-57$ to 60$]$ \\
\hline
\end{tabular}




\section{Discussion}

Actually, LT configures as a challenge to improve HRQoL, functional capacity and survival among patients suffering from severe pulmonary diseases. In our study, we report the HRQoL trajectory from the time of entry in the waiting list before LT and over the first 2 years after LT in a single-center longitudinal cohort. We further assessed functional capacity and survival among these patients. Among the 57 patients who received LT and survived at the 6 months follow-up, LT led to a significant improvement in HRQoL and psychological status that persisted over time. This coincides with the results reported in the literature $[3,26]$. This was particularly evident in the physical component of HRQoL, as shown by the high proportion of subjects who reported changes in SF-36 PCS and SGRQ total scores, within the first six months. When considering factors such as age, gender, and type of LT, only the last one (specifically, having a unilateral transplantation) showed a significant negative impact on the PCS trajectory in our sample. Functional performance (6MWT distance and FEV1\% predicted) significantly improved over time and was strongly associated with the PCS and SGRQ total scores. Furthermore, among patients enrolled in our study, we found a mortality rate of 18 per 100 person-years after LT, which is in line with data reported from international registries. Just as found by Vermeulen et al. [27], in our sample, pretransplant HRQoL did not predict survival after LT, although mortality tended to be slightly higher among patients with lower HRQoL at the pre-LT assessment. Factors such as age, sex, type of LT, FEV1\% predicted, 6MWT distance, and GHQ score at pre-transplant assessment did not influence the relation between pre-LT HRQoL and survival.

Regarding the HRQoL trajectory over time, we must underline that PCS score remained below the population norm throughout the followup, which is consistent with previous studies reporting on changes in the physical health and functioning domains of HRQoL after LT [1]. However, some previous studies showed that HRQoL after transplantation became comparable to that of the general population [28,29]. Our results are further supported by the changes in the SGRQ activity score, which showed the lowest improvement among the subscales.

Notably, the SF-36 MCS score, which was similar to the norm before LT, showed small and non-significant changes during follow-up. This has also been reported by others [10]. In contrast to the PCS and SGRQ scores, the MCS score showed a similar profile in survivors and non-survivors throughout the follow-up period. This behavior might be partially explained by the particular features of the transplant experience. MCS was paradoxically high while on the waiting list for LT, a life extending

Table 4. Association of pre-LT HRQoL and midterm survival after LT.

\begin{tabular}{|c|c|c|c|c|c|}
\hline HRQOL & Level & Deaths n (\%) & $\begin{array}{l}\text { Rate per } 100 \text { person-years } \\
\qquad(95 \% \mathrm{CI})\end{array}$ & HR $(95 \%$ CI $)$ & $\mathbf{P}$ \\
\hline \multirow[t]{2}{*}{ SF-36 PCS } & Best 25.9-49.5 & $22(46)$ & $16.66(11-25)$ & 1 & 0.46 \\
\hline & Worst 13.2-25.7 & $10(50)$ & $22.3(12-41)$ & $1.33(0.62-2.85)$ & \\
\hline \multirow[t]{2}{*}{ SF-36 MCS } & Best 45.8-72.6 & $22(46)$ & $17.7(11.6-27.0)$ & 1 & 0.54 \\
\hline & Worst 25.6-45.1 & $10(50)$ & $19.0(10-35)$ & $1.28(0.59-2.77)$ & \\
\hline \multirow[t]{2}{*}{ SGRQ Overall } & Best 17.7-76.2 & $20(42.5)$ & $16.5(10.6-25.5)$ & 1 & 0.55 \\
\hline & Worst 76.4-95.0 & $12(57)$ & $21.6(12.3-38)$ & $1.25(0.60-2.60)$ & \\
\hline \multirow[t]{2}{*}{ SGRQ Symptoms } & Best 4.4-70.4 & $19(40)$ & $15.4(9.8-24)$ & 1 & 0.51 \\
\hline & Worst 70.6-97.5 & $13(60)$ & $24.4(14.2-42)$ & $1.28(0.61-2.66)$ & \\
\hline \multirow[t]{2}{*}{ SGRQ Activities } & Best $30.0-92.5$ & $26(43)$ & $17.2(11.7-25.2)$ & 1 & 0.87 \\
\hline & Worst $94.2-100$ & $6(75)$ & $23.3(10.5-51.8)$ & $1.07(0.42-2.7)$ & \\
\hline \multirow[t]{2}{*}{ SGRQ Impact } & Best 6.7-69.3 & $19(41)$ & $16.3(10.4-25.6)$ & 1 & 0.50 \\
\hline & Worst 69.7-96.2 & $13(59)$ & $21.5(12.5-36.9)$ & $1.28(0.62-2.64)$ & \\
\hline
\end{tabular}

Table 5. Associations of $\mathrm{a} \geq 50 \%$ change in $\mathrm{HRQoL}$ and $\mathrm{HRQoL}$ as a continuous value at 6 months after LT with midterm survival.

\begin{tabular}{|c|c|c|c|c|c|c|c|}
\hline \multirow[t]{2}{*}{ HRQOL variable } & \multicolumn{5}{|c|}{ Dichotomized values } & \multicolumn{2}{|c|}{ Continuous values* } \\
\hline & Change & Death n (\%) & $\begin{array}{l}\text { Rate per } 100 \text { person-years } \\
\qquad(95 \% \mathrm{CI})\end{array}$ & HR $(95 \%$ CI $)$ & p & HR $(95 \%$ CI) & p \\
\hline \multirow[t]{2}{*}{ SF-36 PCS } & $<50$ & $13(56)$ & $19(11-33)$ & 1 & 0.34 & $0.96(0.90-1.01)$ & 0.10 \\
\hline & $\geq 50$ & $5(29)$ & $11(5-27)$ & $0.61(0.21-1.74)$ & & & \\
\hline \multirow[t]{2}{*}{ SF-36 MCS } & $<50$ & $17(44)$ & $15(10-25)$ & 1 & 0.31 & $0.95(0.90-1.00)$ & 0.07 \\
\hline & $\geq 50$ & $1(100)$ & $43(6-308)$ & $3.53(0.43-29.14)$ & & & \\
\hline \multirow[t]{2}{*}{ SGRQ Overall } & $<50$ & $11(65)$ & $36(20-65)$ & 1 & 0.01 & $0.97(0.94-0.99)$ & 0.01 \\
\hline & $\geq 50$ & $8(32)$ & $10(5-20)$ & $0.28(0.11-0.74)$ & & & \\
\hline \multirow[t]{2}{*}{ SGRQ Symptoms } & $<50$ & $11(73)$ & $32(18-58)$ & 1 & 0.07 & $0.97(0.96-0.99)$ & 0.01 \\
\hline & $\geq 50$ & $8(30)$ & $10(5-20)$ & $0.41(0.15-1.09)$ & & & \\
\hline \multirow[t]{2}{*}{ SGRQ Activity } & $<50$ & $16(64)$ & $25(15-41)$ & 1 & 0.07 & $0.98(0.96-1.00)$ & 0.03 \\
\hline & $\geq 50$ & $3(18)$ & $6(2-19)$ & $0.31(0.88-1.09)$ & & & \\
\hline \multirow[t]{2}{*}{ SGRQ Impact } & $<50$ & $8(50)$ & $26(13-52)$ & 1 & 0.25 & $0.98(0.96-1.00)$ & 0.07 \\
\hline & $\geq 50$ & $11(42)$ & $13(7-24)$ & $0.56(0.21-1.48)$ & & & \\
\hline
\end{tabular}

*Linearity was verified. 
procedure that generates strong expectations among patients when compared with other end stage diseases. However, it would remain within the norm after LT, even as patients cope with complicated posttransplant medical regimens and treatment side effects, because of a revision in patients' HRQoL standards: patients would be more conscious of the fact that their lives had been prolonged thanks to a gift that implied another person's death [15,30]. This further explains why MCS pattern did not change over time in either survivors or non-survivors.

In a recent review of studies published between 1994 and 2013 on HRQoL after LT [31], only 3 studies were found to focus on the psychological status among adult lung recipients. Thus, we expanded on these findings by including GHQ scores. Notably, a high percentage of study participants reported a score above 4 at baseline, thus suggesting psychological impairment. However, significant improvements were observed in GHQ score following LT. Santana et al. [26] found similar results with a different instrument -namely, a significant reduction in depressive symptoms following LT at 6 months follow-up compared to pre-LT levels. This result is likely to be very interesting when considering the clinical and social relevance of these patients' care. In fact, because of the need to further reduce healthcare expenditures, ensuring that LT recipients have good psychological and social wellbeing would be beneficial, as it could help to reduce their length of stay in hospitals with major responsibility of family caregivers.

The MCS score was strongly associated with psychological distress as assessed by the GHQ. Compared to the MCS score, which remained relatively stable over time, the GHQ was more sensitive to highlighting the presence of distress in our patient sample at baseline and its improvement over the first six months after LT. In the literature, there is little evidence of the precise involvement of mental health in LT outcomes. Recently, Dew et al. [15] focused on anxiety disorders after LT, and concluded that lung and cardiothoracic recipients appear more susceptible to panic disorders and panic-related depression. However, there is little consensus with respect to the psychometric instruments used in such investigations.

Patients with better HRQoL at 6 months tended to survive longer. However, our sample evidently lacked sufficient power. Furthermore, only changes in SGRQ total scores reached statistical significance. This might be explained by the fact that this questionnaire is disease specific and thus could better describe the evolution of pulmonary disease. Researchers [31] have considered the SGRQ one of the best lung-specific questionnaires, as it is able to concisely assess the symptoms and functional wellbeing of patients with pulmonary pathologies. Given the heterogeneity of HRQoL instruments used in the past, we believe our results might support the sole employment of the SGRQ when following-up on lung recipients. In fact, this questionnaire could be useful for identifying red flags about transplantation outcomes, and the use of a single, disease-specific HRQoL instrument during follow-up might reduce the time needed for investigation, thereby allowing physicians to better focus on other aspects of clinical practice.

Employment rate following LT in our study sample is in line with recent findings from a large cohort reported by Tumin et al. [32]. Return to work is a major point in the recovery after lung transplantation, due to its impact on patients' survival, quality of life and mental health [32,33].

Our findings are limited by the relatively small case series, further restricted by the early post transplant mortality. Although study results require confirmation in a larger clinical sample, the following points must be highlighted. First, the single-center design guarantees that clinical management was uniform. Specifically, the in-depth evaluation was done by the same team, which is not always possible in large multicenter studies. Second, all questionnaires were completed during follow-up visits under the same conditions (i.e., no questionnaires were mailed). Third, we employed a multidimensional approach in- volving standardized and validated instruments to investigate generic and disease-specific HRQoL as well as psychological and functional status [7]. Finally, an extensive longitudinal design was applied, thereby allowing a direct comparison of HRQoL before and up to 2 years after LT in the same patients.

In conclusion, according to our results and those of previous studies, the first 6 months after LT are critical for transplant patients, both in terms of their functional performance and HRQoL, that reflects subjective wellbeing. Thus, HRQoL evaluations appear to be central to followups of LT candidates and recipients, as they give a clear understanding of the patient's perspective [5]. Moreover, considering the huge effort it takes to retain patients for long-term follow-ups and the stabilization of HRQoL within the first six months post-LT, it could be useful to focus on identifying HRQoL in these first few months after LT to determine which patients will require greater attention in terms of their functional capacity and wellbeing in subsequent follow-ups. The SGRQ might also be useful during follow-up because of its greater specificity in targeting respiratory symptoms and the functional wellbeing of these patients. This is relevant for the prospect of containing healthcare costs and rationalization of human resources.

\section{References}

1. Finlen Copeland CA, Vock DM, Pieper K, et al. Impact of lung transplantation on recipient quality of life: a serial, prospective, multicenter analysis through the first posttransplant year. Chest 2013:143:744-50.

2. http://www.ishlt.org/registries/quarterlyDataReport.asp.

3. Myaskovsky L, Dew MA, McNulty ML, et al. Trajectories of change in quality of life in 12-month survivors of lung or heart transplant. Am J Transplant 2006:6:1939-47.

4. http://www.trapianti.salute.gov.it

5. Burra P, De Bona M, Germani G, et al. The concept of quality of life in organ transplantation. Transplant Proc 2007:29:2285-7.

6. Goetzmann L, Klaghofer R, Wagner-Huber R, et al. Quality of life and psychosocial situation before and after a lung, liver or an allogeneic bone marrow transplant. Swiss Med Wkly 2006:136:281-90.

7. Singer JP, Chen J, Blanc PD, et al. A thematic analysis of quality of life in lung transplant: the existing evidence and implications for future directions. Am J Transplant 2013:13:839-50.

8. Kugler C, Strueber M, Tegtbur U, et al. Quality of life 1 year after lung transplantation. Prog Transplant 2004:14:331-6.

9. Lanuza DM, Lefaiver CA, Brown R, et al. A longitudinal study of patients' symptoms before and during the first year after lung transplantation. Clin Transplant 2012:26:576-89.

10. Rutherford RM, Fisher AJ, Hilton C, et al. Functional status and quality of life in patients surviving 10 years after lung transplantation. Am J Transplant 2005;5:1099-104.

11. Goldberg DP, Hillier VF. A scaled version of the General Health Questionnaire. Psychol Med. 1979:9:139-45.

12. Bellantuono C, Fiorio R, Zanotelli R, Tansella M. Psychiatric screening in general practice in Italy. A validity study of the GHQ. Soc Psychiatry 1987:22:113-7.

13. Fontanesi F, Gobetti C, Zimmermann-Tansella C, Tansella M. Validation of the Italian version of the GHQ in a general practice setting. Psychol Med 1985:15:411-5.

14. Smith PJ, Blumenthal JA, Carney RM, et al. Neurobehavioral functioning and survival following lung transplantation. Chest 2014:145: 604-11.

15. Dew MA, DiMartini AF, DeVito Dabbs AJ, et al. Onset and risk factors for anxiety and depression during the first 2 years after lung transplantation. Gen Hosp Psychiatry 2012:34:127-138. 
16. Apolone G, Mosconi P. The Italian SF-36 Health Survey: translation, validation and norming. J Clin Epidemiol 1998:51:1025-36.

17. Ware JE, Snow KK, Kosinski M, Gandek B. SF-36 health survey: Manual and interpretation guide. Boston: The Health Institute; 1993.

18. Ware J, Kosinski M, Keller S. SF-36 physical and mental health summary scales: a user's manual. Boston: The Health Institute; 1994.

19. Ware JE Jr, Kosinski M, Gandek B, et al. The factor structure of the SF-36 Health Survey in 10 countries: results from the IQ0LA Project. International Quality of Life Assessment. J Clin Epidemiol 1998;51:1159-65.

20. Ricotti S, Vitulo P, Petrucci L, et al. Determinants of quality of life after lung transplant: an Italian collaborative study. Monaldi Arch Chest Dis 2006;65:5-12.

21. Carone M, Bertolotti G, Anchisi F, et al. Analysis of factors that characterize health impairment in patients with chronic respiratory failure. Quality of Life in Chronic Respiratory Failure Group. Eur Respir J 1999:13:1293-300.

22. Carone M, Bertolotti G, Anchisi F, et al. Il Saint George's Respiratory Questionnaire (SGRQ): la versione Italiana. Rass Mal App Resp 1999:14:31-7.

23. Jones PW, Quirk FH, Baveystock CM, Littlejohns P. A self-complete measure for chronic airflow limitation - the St George's Respiratory Questionnaire. Am Rev Respir Dis 1992:145:1321-7.

24. George D, Mallery P. SPSS for Windows step by step: A simple guide and reference. 11.0 update. 4th ed. Boston: Allyn \& Bacon; 2003.
25. Norman GR, Sloan JA, Wyrwich KW. Interpretation of changes in health related quality of life: the remarkable universality of half a standard deviation. Med Care 2003:41:582-92.

26. Santana MJ, Feeny D, Jackson K, et al. Improvement in health-related quality of life after lung transplantation. Can Respir J 2009:16:153-8.

27. Vermeulen KM, TenVergert EM, Verschuuren EA, et al. Pre-transplant quality of life does not predict survival after lung transplantation. J Heart Lung Transplant 2008:27:623-7.

28. Vermeulen KM, van der Bij W, Erasmus ME, TenVergert EM. Longterm health-related quality of life after lung transplantation: different predictors for different dimensions. J Heart Lung Transplant 2007:26:188-93.

29. Stavem K, Bjortuft 0, Lund MB, et al. Health-related quality of life in lung transplant candidates and recipients. Respir Int Rev Thorac Dis 2000:67:159-65.

30. Goetzmann L, Sarac N, Ambuhl P, et al. Psychological response and quality of life after transplantation: a comparison between heart, lung, liver and kidney recipients. Swiss Med Wkly 2008:138:477-83.

31. Seiler A, Klaghofer R, Ture M, et al. A systematic review of healthrelated quality of life and psychological outcomes after lung transplantation. J Heart Lung Transplant 2016:35:195-202.

32. Tumin D, Kirkby SE, Tobias JD, et al. Attained functional status moderates survival outcomes of return to work after lung transplantation. Lung 2016;194:437-45.

33. Petrucci L, Ricotti S, Michelini I, et al. Return to work after thoracic organ transplantation in a clinically-stable population. Eur J Heart Fail 2007;9:1112-9. 